Research Article

\title{
Prediction of Soil Water Characteristic Curve Based on Soil Water Evaporation
}

\author{
Gaoliang Tao $\mathbb{D}^{1,2}$ Da Lei, ${ }^{1}$ Lisheng Liu, ${ }^{2}$ Yi Li, ${ }^{1}$ and Xueliang Zhu ${ }^{1}$ \\ ${ }^{1}$ School of Civil Engineering, Architecture and Environment, Hubei University of Technology, Wuhan, Hubei 430068, China \\ ${ }^{2}$ School of Urban Construction, Wuchang University of Technology, Wuhan, Hubei 430223, China \\ Correspondence should be addressed to Gaoliang Tao; tgl1979@126.com
}

Received 16 December 2020; Revised 10 February 2021; Accepted 14 February 2021; Published 2 March 2021

Academic Editor: Jian Xu

Copyright (C) 2021 Gaoliang Tao et al. This is an open access article distributed under the Creative Commons Attribution License, which permits unrestricted use, distribution, and reproduction in any medium, provided the original work is properly cited.

Soil water characteristic curves (SWCC) and soil water evaporation curves both represent the laws of water content variation in the natural state. Aiming to investigate the relationship between them further, Hunan sand with six dry densities were used in this study, and a series of experimental studies were performed. This study developed the application of evaporation curves in geotechnical engineering, reduced the workload of measuring soil water characteristic curves, and explored the relationship between evaporation rate and fractal dimension. Through the indoor tests, we measured soil water characteristic curves of specimens and soil water evaporation curves at different temperatures and explored the relationship between these two curves. In this study, a model was developed that allows the conversion from soil water evaporation curves to soil water characteristic curves, which is an equation about matrix suction $\psi$ versus cumulative time $t$. Further, two prediction methods are developed, which are derived based on the Fredlund-Xing model and based on the Bird model, respectively. The proposed methods were validated using soil water evaporation tests of Hunan sand with six dry densities at three ambient temperatures, and the results showed that good prediction performances were achieved using these two methods.

\section{Introduction}

Unsaturated soil is a three-phase porous medium composed by soil particles, water, and gas. The contents of soil constituents strongly impact its engineering properties, among which water content is directly related to the engineering properties, such as pore structure, strength, and permeability coefficient. Under natural conditions, the soil water evaporation causes some undesirable phenomena in the foundation, such as shrinkage, settlement, cracking, which leads to the destruction of the building structure on the foundation, eventually [1-4].

In geotechnical and environmental engineering, many engineering problems involve consideration of water transport, fluid flow, and heat transfer in the soil. Therefore, the evaporation of porous media has an extremely important influence on their engineering performance [5]. The soil water evaporation is a dynamic process that shows a decreasing trend of water content as the accumulation time increases. Currently, the more popular test methods are the indoor test methods, which is easy to control each variable, and results can be better applied to theoretical studies. The indoor test is a simulation of the soil water evaporation process in a stable environment, and it can effectively measure the changes in water content under the effect of evaporation [4]. Similarly, soil water characteristic curves are often used to describe the water retention capacity of unsaturated soils. Under the dewetting path, the soil water characteristic curves indicate that water contents decrease with increasing matrix suction $[6,7]$. The results of soil water evaporation tests and soil water characteristic curve tests (SWCCs) show that these two curves have many same performances, which means there are some correlation between them. The study of this interconnection facilitates the applications of evaporation curves and soil water characteristic curves in practical engineering and reduces the workload of experimental measurements. 
In this study, an equation related to the cumulative time $t$ and the matrix suction $\psi$ is derived based on the Menger sponge model. Using this equation to transform the variable $t$ of the evaporation curve into $\psi$ yields the predicted value of the soil water characteristic curve; that is, the evaporation curve converted into the soil water characteristic curve by this equation. In addition, we applied this method with two soil water characteristic curve models to develop methods for predicting soil water characteristic curves based on soil water evaporation, which broadened its application in practical engineering. Moreover, Hunan sand specimens with six dry densities were used for validation, and the results showed that this method has good prediction performance.

\section{Materials and Methods}

2.1. Test Materials. The soil samples used in the tests are Hunan sand, which were taken from the Ziquejie terraces in Xinhua County, Hunan Province. The relevant parameters of physical property of Hunan sandy soil are shown in Table 1.

2.2. Soil Water Evaporation Test. At present, the methods to determine the evaporations or evaporation rates of specimens include theoretical calculation method and direct measurement method [8]. The theoretical calculation method is based on some theoretical models, such as Dalton [9], Penman [10], Fox [11], and Denisov et al. [12], which investigated the influence of many factors on soil water evaporation. The direct measurement methods measure the variation of water content using test instruments, which can be divided into in situ test methods and indoor test methods [13]. Indoor tests directly measure the weight losses of soil to obtain evaporation curves, and this method usually performed using electronic scales or sensors [14]. In situ test is a method to measure the volume of soil water evaporation on location using equipment such as drainage lysimeters and microlysimeters. In this study, the evaporations of specimens were measured using an indoor test, which was performed as follows.

The Hunan sand was dried and crushed, and then soil particles with the size of less than $2 \mathrm{~mm}$ were sieved for testing. Add water to dry soil and mix well, then put it in a sealed bag, and let it stand for 72 hours, waiting for the moisture transport to a uniform water content. Three groups of six specimens with different dry densities were made for the soil water evaporation test. The cutting ring used in this test has an inner diameter of $61.8 \mathrm{~mm}$ and a height of $20 \mathrm{~mm}$. In this experiment, three ambient temperatures are set to investigate the influences of temperature on evaporation laws. The plan of this experiment and variables are shown in Table 2. The soil water evaporation tests were performed in an electric oven and the weight of specimens with an electronic scale was measured; the experimental equipment is shown in Figure 1. The top surface of the specimen is exposed to air and the bottom surface is sealed with a film, which allows each sample under the same testing environment and helps to avoid testing errors caused by soil particles falling off during the process of drying. The prepared specimens were put into the electric oven (the temperature error of the oven was less than $\pm 0.5^{\circ} \mathrm{C}$ ), and the specimens were weighed and recorded at regular intervals.

2.3. Soil Water Characteristic Curve Experiments. Six specimens with the same parameters as in the soil water evaporation test were applied to perform soil water characteristic curve experiments. This experiment uses a pressure plate apparatus to measure the soil water characteristic curves of the specimens, which is manufactured by Soilmoisture Corporation, USA, and it is composed of pressure chamber, high air entry value ceramic plate, pressure gauge, gas source, and a water catcher, as shown in Figure 2. The prepared specimen on the ceramic plate in the pressure chamber was placed and a good contact between them was ensured, and then the pressure chamber is closed. When a certain pressure is applied to the pressure chamber, based on the axis-translation technique, the water in the sample is gradually drained through the ceramic plate until the specimen reaches equilibrium. At this time, taking out the soil samples and weighing them, the water content corresponding to this suction can be worked out, thereby the soilwater characteristic curves of Hunan sand are obtained. In this experiment, a series of 9 levels of air pressure were applied to the Hunan sand specimens, in the order of $5 \mathrm{kPa}$, $10 \mathrm{kPa}, 30 \mathrm{kPa}, 80 \mathrm{kPa}, 160 \mathrm{kPa}, 280 \mathrm{kPa}, 450 \mathrm{kPa}, 700 \mathrm{kPa}$, and $1250 \mathrm{kPa}$.

\section{Experimental Results and Analysis}

3.1. Analysis of Soil Water Evaporation Test Results. The change rules of water content during soil water evaporation were calculated based on the measured weight of specimens, and the results are shown in Figure 3. The drainage process was consistent across the specimens at the three ambient temperatures, and they were all clearly distinguished into three stages, that is, two stages of linear variation and a transition stage. Tang et al. [4] divided the water evaporation process into three phases, namely, constant rate phase, deceleration rate phase, and residual phase. The constant rate phase occurs at the beginning of the soil water evaporation test, where the evaporation rate is the largest and constant. In this process, free water is removed from the soil, and the ambient temperature, air humidity, and wind speed are the dominant factors affecting the evaporation rate at this stage $[4,15]$. The water transports on the planar surface of soil are dominated by the percolation of capillary water. As the water content of the soil decreases, free and capillary water is gradually discharged and the evaporation rate slows down; this process is known as the deceleration rate phase. In this stage, the evaporation rate is related to water content. The residual phase is the last stage of soil water evaporation. At this time, the water content of soil is very low, and connectivity between pores is poor, while the diffusion of water vapor is hindered, so the evaporation rate is very small. 
TABLE 1: Physical parameters of soil samples used in the study.

\begin{tabular}{|c|c|c|c|c|c|c|c|c|}
\hline \multirow{2}{*}{ Name } & \multirow{2}{*}{ Texture } & \multirow{2}{*}{ Specific gravity } & \multirow{2}{*}{ Liquid limit (\%) } & \multirow{2}{*}{ Plastic limit (\%) } & \multicolumn{4}{|c|}{ Percentage of particles (\%) } \\
\hline & & & & & Gravel & Sand & Silt & Clay \\
\hline Hunan sand & Sandy loam & 2.7155 & 28.11 & 23.32 & 15.92 & 80.98 & 1.73 & 1.37 \\
\hline
\end{tabular}

TABLE 2: Soil water evaporation test variables.

\begin{tabular}{|c|c|c|c|c|c|c|c|}
\hline Name & $\begin{array}{l}\text { Dry density } \\
\left(\mathrm{g} / \mathrm{cm}^{3}\right)\end{array}$ & $\begin{array}{c}\text { Specimen } \\
\text { number }\end{array}$ & Temperature $\left({ }^{\circ} \mathrm{C}\right)$ & $\begin{array}{c}\text { Specimen } \\
\text { number }\end{array}$ & Temperature $\left({ }^{\circ} \mathrm{C}\right)$ & $\begin{array}{c}\text { Specimen } \\
\text { number }\end{array}$ & $\begin{array}{c}\text { Temperature } \\
\left({ }^{\circ} \mathrm{C}\right)\end{array}$ \\
\hline \multirow{6}{*}{$\begin{array}{l}\text { Hunan } \\
\text { sand }\end{array}$} & 1.30 & $\mathrm{H} 1-\mathrm{a}$ & \multirow{6}{*}{25} & $\mathrm{H} 1-\mathrm{b}$ & & $\mathrm{H} 1-\mathrm{c}$ & \multirow{6}{*}{36} \\
\hline & 1.35 & $\mathrm{H} 2-\mathrm{a}$ & & $\mathrm{H} 2-\mathrm{b}$ & & $\mathrm{H} 2-\mathrm{c}$ & \\
\hline & 1.40 & $\mathrm{H} 3-\mathrm{a}$ & & $\mathrm{H} 3-\mathrm{b}$ & & $\mathrm{H} 3-\mathrm{c}$ & \\
\hline & 1.45 & $\mathrm{H} 4-\mathrm{a}$ & & $\mathrm{H} 4-\mathrm{b}$ & 30 & $\mathrm{H} 4-\mathrm{c}$ & \\
\hline & 1.50 & H5-a & & $\mathrm{H} 5-\mathrm{b}$ & & $\mathrm{H} 5-\mathrm{c}$ & \\
\hline & 1.60 & H6-a & & H6-b & & H6-c & \\
\hline
\end{tabular}

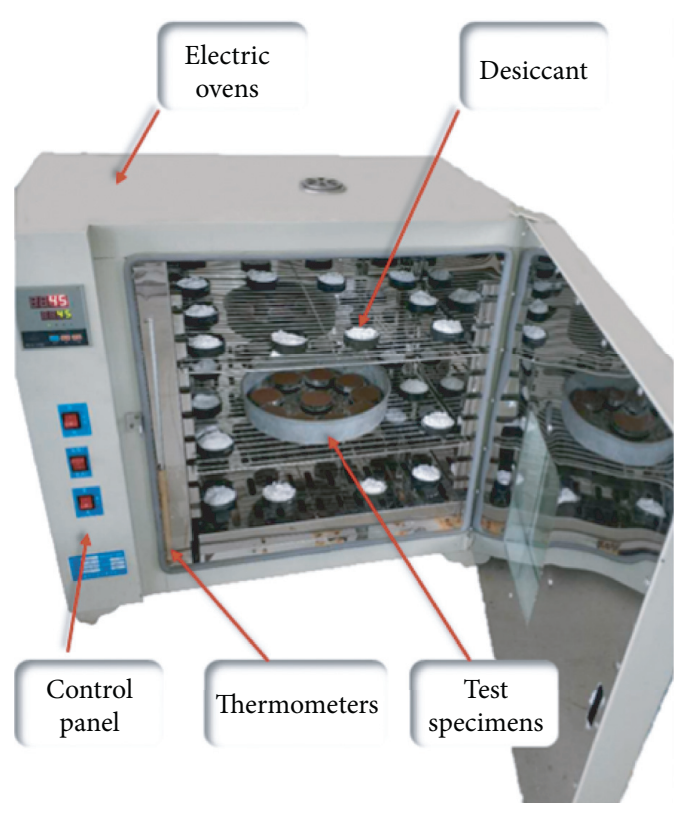

(a)

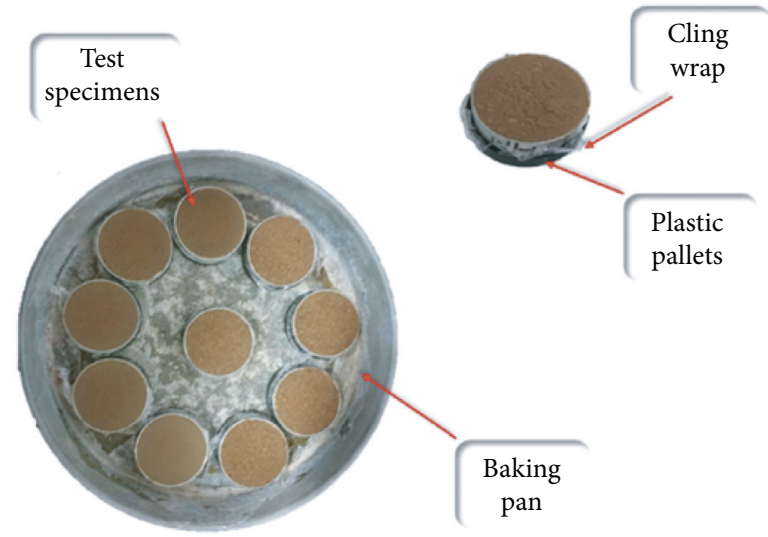

(b)

FIgURE 1: Soil water evaporation experiment. (a) The electric oven. (b) Soil samples.

The evaporation rate for the constant rate phase can be obtained by using a linear fit to measured data, denoted by $v_{e}$, and its value is equal to the evaporation of water per unit weight of soil particles. Figure 4 shows the evaporation rates of soil samples at different temperatures, it indicates that the evaporation rates increase as the temperature rises, and the evaporation rates soil samples with higher dry density are smaller. In general, the evaporation rates have a significant positive correlation with the ambient temperature, which is consistent with the experimental results of Tang et al. [4].

3.2. Analysis of Soil Water Characteristic Curve Test Results. The soil water characteristic curves of Hunan sand at six dry densities are shown in Figure 5, and the test results are expressed in the form of mass water content. While with the lower matrix suction, the water content of specimens with smaller dry density is higher. When the matrix suction is higher than $5 \mathrm{kPa}$, the water content with suction changes in the same law at different densities.

\section{Application of Soil Water Evaporation Curves in Predicting Soil Water Characteristic Curves}

4.1. Relationship between Evaporation Curves and SWCCs. In three-dimensional space, according to the Menger sponge model, the expression for the cumulative volume $V(\geq d)$ is as follows [16]: 


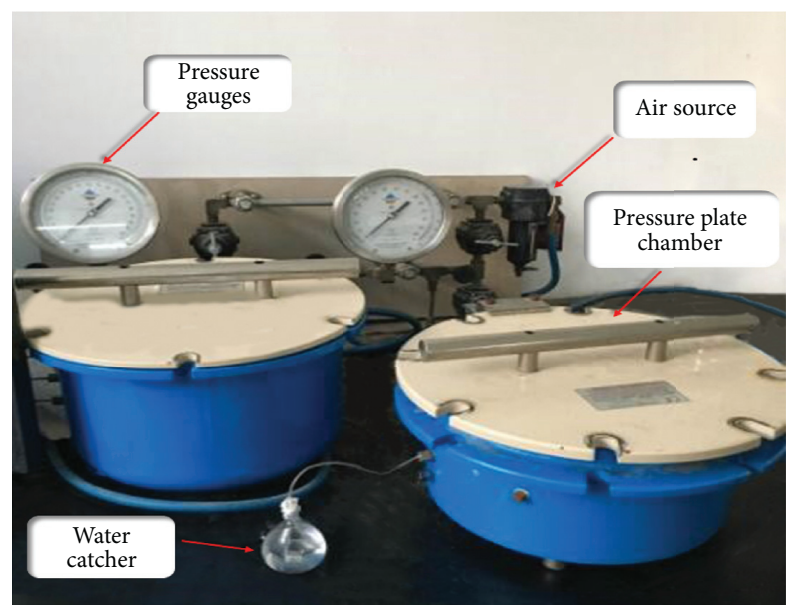

(a)

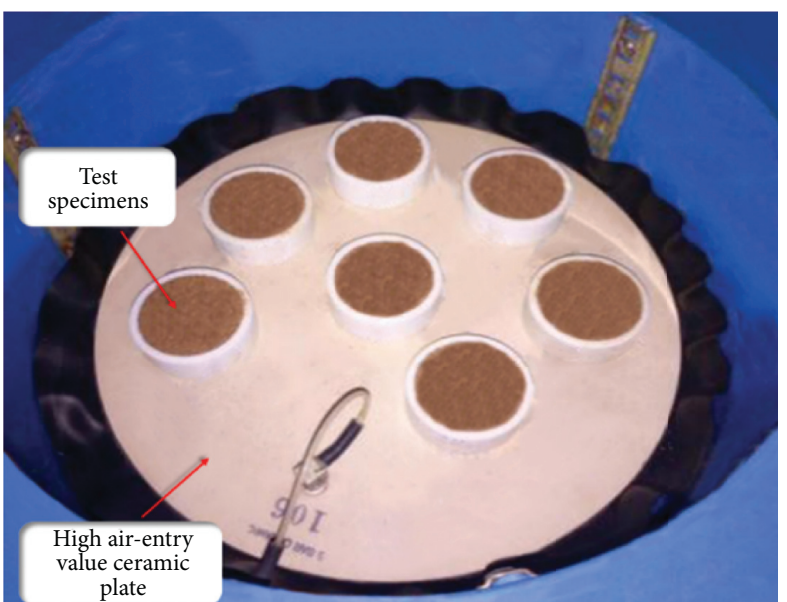

(b)

Figure 2: The devices of soil water characteristic curve test. (a) Pressure plate apparatus. (b) Test specimens.

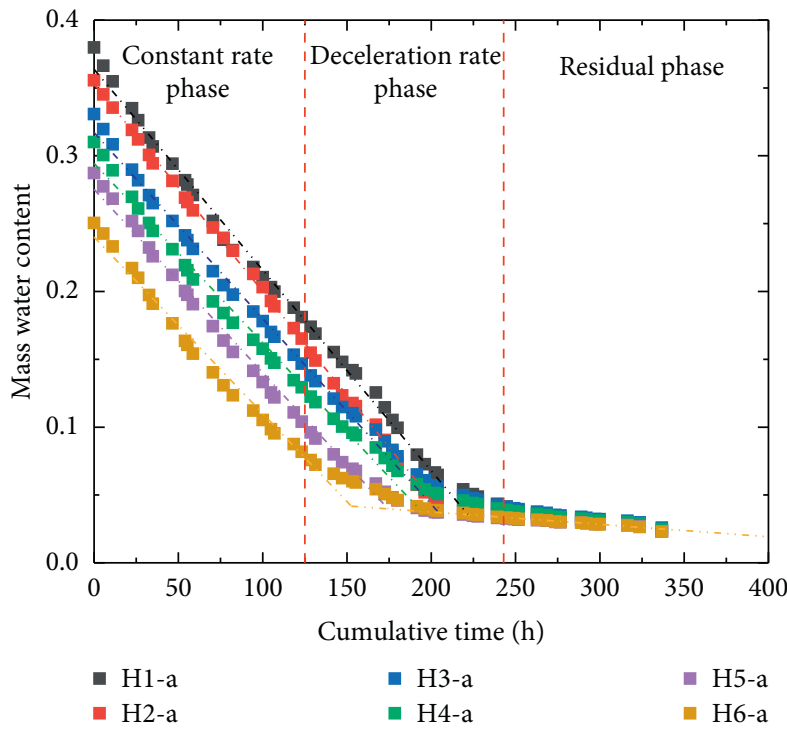

(a)

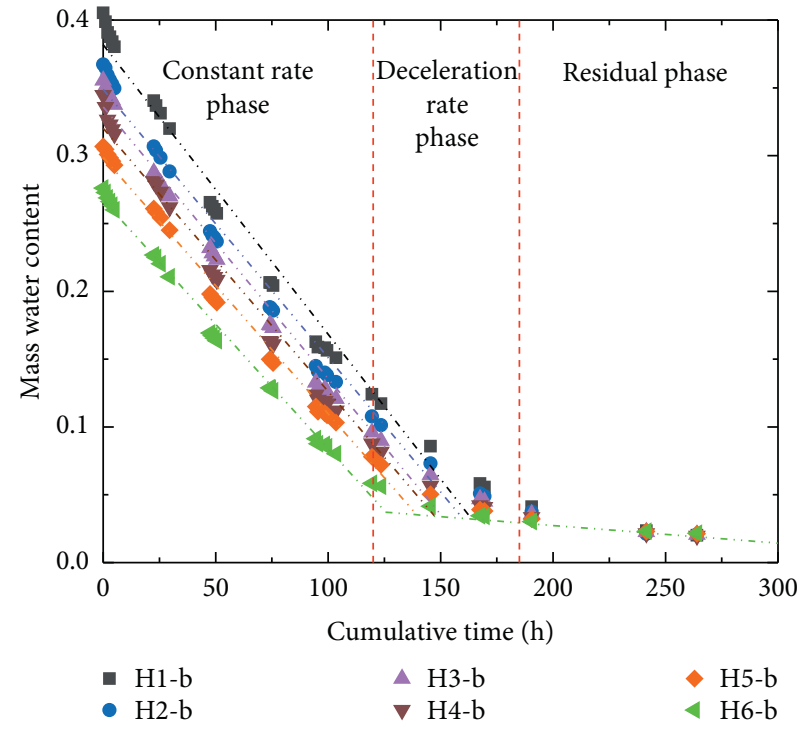

(b)

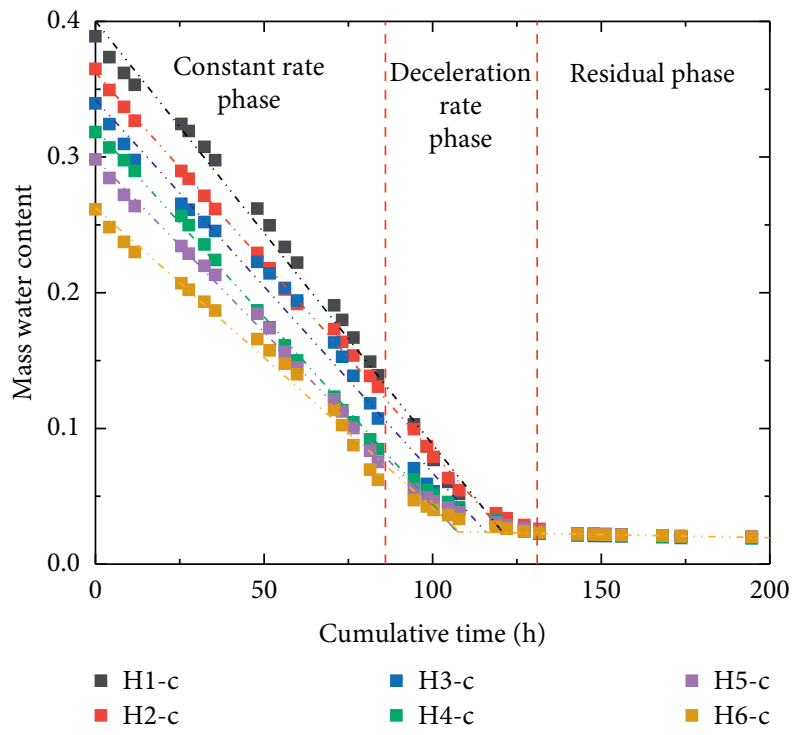

(c)

Figure 3: Results of soil water evaporation experiments. (a) $25^{\circ} \mathrm{C}$ ambient temperature. (b) $30^{\circ} \mathrm{C}$ ambient temperature. (c) $36^{\circ} \mathrm{C}$ ambient temperature. 


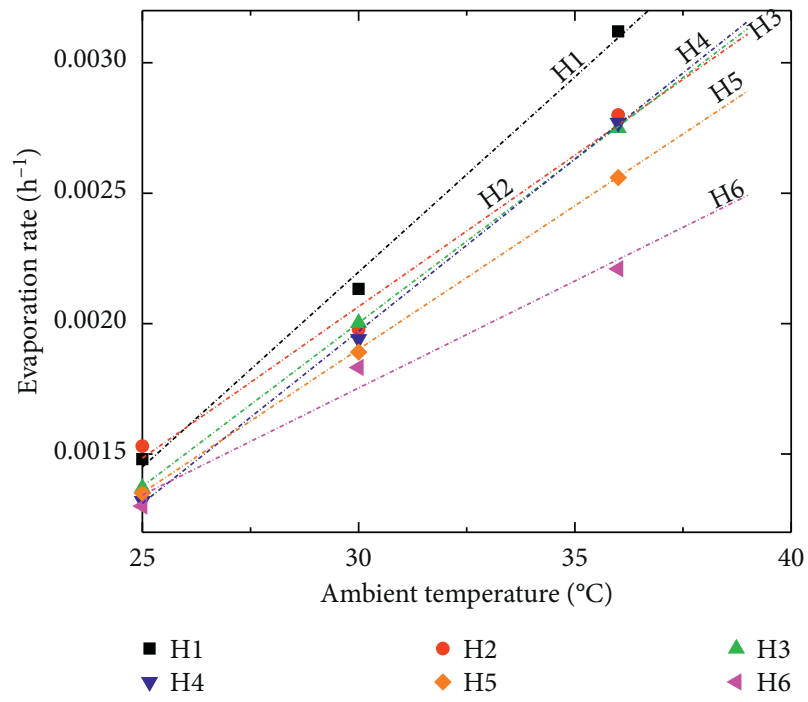

FIgURE 4: Evaporation rates of soil samples with different dry densities. H1-H6 indicates the soil samples with a dry density of $1.30 \mathrm{~g} / \mathrm{cm}^{3}, 1.35 \mathrm{~g} / \mathrm{cm}^{3}, 1.40 \mathrm{~g} / \mathrm{cm}^{3}, 1.45 \mathrm{~g} / \mathrm{cm}^{3}, 1.50 \mathrm{~g} / \mathrm{cm}^{3}$, and $1.60 \mathrm{~g} / \mathrm{cm}^{3}$, respectively.

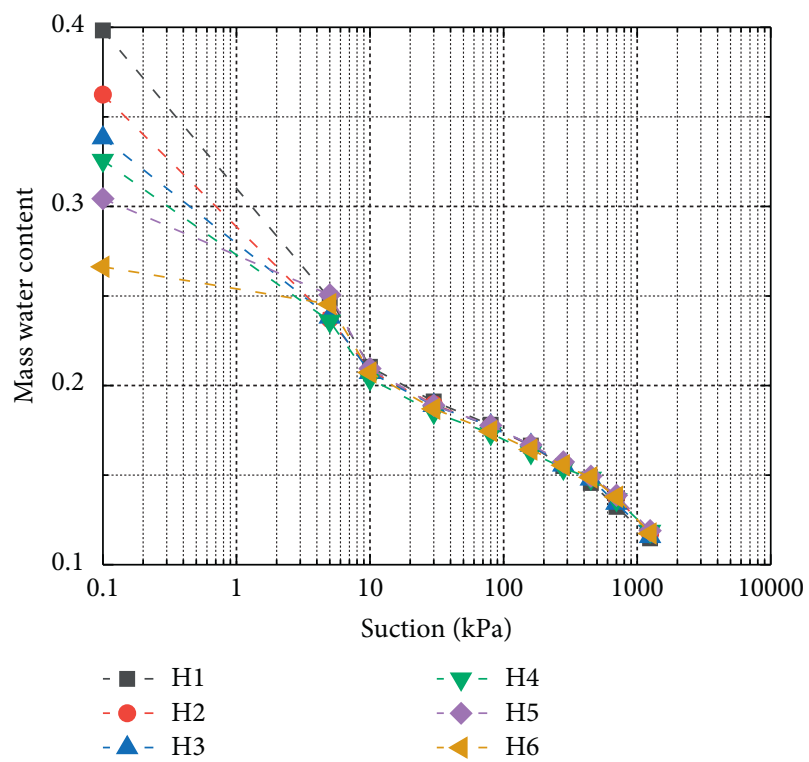

Figure 5: The results of soil water characteristic curve test.

$$
V(\geq d)=V_{a}\left[1-\left(\frac{d}{L_{2}}\right)^{3-D}\right]
$$

where $d$ is the pore diameter, $V_{\mathrm{a}}$ is the volume of the research object, and $L_{2}$ is the size of the measured range. Katz and
Thompson [17] showed that $L_{2}$ is the upper limit of the selfsimilarity in the sample. This study is based on the Menger sponge model to investigate the variation of soil water content; therefore, $L_{2}$ should be taken as $1 / \rho_{\mathrm{d}}, \rho_{\mathrm{d}}$ is the dry density of the specimen, and $D$ is the fractional dimension of the sample [16]. For soil with fractal properties, the fractal dimension is usually calculated using the box counting approach [18] or ideal particle pore-space geometry assumptions (e.g., Menger sponge and Sierpinski carpet) [16]. In recent years, published studies have developed some methods using soil water characteristic curves to calculate the soil fractal dimensions [19].

In a unit weight of soil skeleton, the time $t$ taken to empty all the water out of the pores with pores diameter is greater than $d$; it is expressed as follows:

$$
t=\frac{\rho_{w} V(\geq d)}{v_{e}}=\frac{V_{a} \rho_{w}}{v_{e}}\left[1-\left(\frac{d}{L_{2}}\right)^{3-D}\right]
$$

in which $v_{e}$ is the evaporation rate and $\rho_{w}$ is the density of the water.

From the Young-Laplace equation, the pore size and the matrix suction can be transformed by the following equation:

$$
\psi=\frac{4 T_{s} \cos \alpha}{d}
$$

where $T_{s}$ is the surface tension of water and $\alpha$ is the contact angle between soil and water.

Substituting (3) into (2) yields

$$
\psi=\frac{4 T_{s} \cos \alpha}{L_{2}}\left(\frac{v_{e}}{V_{a} \rho_{w}}\right)^{1 / D-3}\left(\frac{V_{a} \rho_{w}}{v_{e}}-t\right)^{1 / D-3} .
$$

\subsection{Prediction Method Based on the Fredlund-Xing Model.} The Fredlund-Xing model [20] is one of the most widely used theoretical models for fitting water soil characteristic curves; it can be applied to a wide variety of soil types with good fitting performance. It is expressed as

$$
w=w_{s}\left[\frac{1}{\ln \left(e+(\psi / a)^{n}\right)}\right]^{m},
$$

where $w_{s}$ is the saturated water content of sample, $a, n$, and $m$ are constants, and their values are obtained by model fitting.

Substituting (4) into (5), the following equation can be obtained. It shows the relationship between the accumulated time $t$ of soil water evaporation and the water content $w$ of soil:

$$
w=w_{s}\left[\frac{1}{\ln \left(e+\left(\left(\left(V_{a} \rho_{w} / v_{e}\right)-t\right) /\left(V_{a} \rho_{w} / v_{e}\right)\left(a L_{2} / 4 T_{s} \cos \alpha\right)^{D-3}\right)^{n / D-3}\right)}\right]^{m} .
$$


The expression of (6) is similar to (5), which indicates some connection between the soil water characteristic curves and the soil water evaporation curves.

The parameters $a_{e c}, m_{e c}$, and $n_{e c}$ are assigned by the following equation:

$$
\begin{aligned}
a_{e c} & =\frac{V_{a} \rho_{w}}{v_{e}}\left(\frac{a L_{2}}{4 T_{s} \cos \alpha}\right)^{D-3}, \\
m_{e c} & =m \\
n_{e c} & =\frac{n}{D-3} .
\end{aligned}
$$

Substituting (7a), (7b), and (7c) into (6) gives the following equation:

$$
w=w_{s}\left[\frac{1}{\ln \left(e+\left(\left(\left(V_{a} \rho_{w} / v_{e}\right)-t\right) / a_{e c}\right)^{n_{e c}}\right)}\right]^{m_{e c}} .
$$

The parameters $m_{e c}$ and $n_{e c}$ are parameters that are uncorrelated with the ambient temperature. In the expression of $a_{e c}$, there are several temperature-related variables, which are $v_{e}, T_{\mathrm{s}}$, and $w$. Therefore, $a_{e c}$ is a parameter related to the ambient temperature. Applying (8) to the soil water evaporation curves at each ambient temperature, $a_{e c}, n_{e c}$, and $m_{e c}$ can be obtained. In addition, the values of $a, n$, and $m$ are obtained by fitting the soil water characteristic curve data using (5). The relationship between $a_{e c}$ versus $a, m_{e c}$ versus $m$, and $n_{e c}$ versus $n$ for each temperature was explored and the results are shown in Figure 6. $a$ versus $a_{e c}$ conforms to (7a) and the shapes of the fitted curves at each temperature are similar. Moreover, the larger the ambient temperature, the smaller the $a_{e c}$. Most of the data for $m$ versus $m_{e c}$ were distributed in the neighboring region of the $y=x$ line, and the sum of squared errors (SSE) was equal to $1.66 \times 10^{-3}$, which indicates that $m_{e c}$ versus $m$ is consistent with (7b). The values of $n_{e c}$ at the three temperatures were fitted using $(7 \mathrm{c})$ and the correlation coefficient was 0.89244 , as shown in Figure 6(c), which indicates that $n_{e c}$ versus $n$ is consistent with $(7 \mathrm{c})$.

Compared with the soil water characteristic curve test, the soil-water evaporation test is easier to be performed and the time required for the test is significantly reduced. It would be convenient to use evaporation curves to directly predict soil water characteristic curves. Using (8) for fitting evaporation curve data to obtain the values of fitting parameters $a_{e c}, n_{e c}$, and $m_{e c}$, the values of $a, m$, and $n$ were calculated by substituting $a_{e c}, n_{e c}$, and $m_{e c}$ into $(7 \mathrm{a})-(7 \mathrm{c})$. Further, the predicted values of the soil water characteristic curve can be obtained from (5), and the results are shown in Figure 7 . The predicted results were in high agreement with the measured data. Differences in the initial water content make the prediction results at each temperature vary in the low suction range. It is because the initial water contents of the specimens are taken as their saturation water contents. Therefore, when using evaporation curves to predict soil water characteristic curves, the initial water content should be kept to the saturation water content as possible.
4.3. Fractal Model-Based Prediction Method. It is feasible to describe the particle distribution, pore surface, and pore volume distribution of the soil with fractal models, and the soil-water characteristic curves derived from the fractal models are consistent with some of the experimental results [19, 21-24]. Bird et al. [24] derived a soil water characteristic curve model for unsaturated soils based on soil-pore fractal models, which has the following expression [25]:

$$
S_{e}=\frac{w-w_{r}}{w_{s}-w_{r}}=\left(\frac{\psi_{a}}{\psi}\right)^{3-D}
$$

where $w_{s}$ is the saturated water content; $w_{r}$ is the residual water content; $\psi_{a}$ is the air entry value; $D$ is the fractional dimension of sample.

Taking the natural logarithm of (9), the following equation can be obtained:

$$
\ln \left(w-w_{r}\right)=\ln \left(w_{s}-w_{r}\right)+(3-D) \ln \frac{\psi_{a}}{\psi} .
$$

In constant rate phase, the relationship between water content $w$ and cumulative time $t$ of the soil water evaporation is shown as the following equation:

$$
w=w_{s}-v_{e} t
$$

Substituting (11) into (10) yields

$$
\ln \left(w_{s}-v_{e} t-w_{r}\right)=\ln \left(w_{s}-w_{r}\right)+(3-D) \ln \frac{\psi_{a}}{\psi} .
$$

Setting the duration of the constant rate phase as $T_{t}$, then $w_{s}=v_{e} T_{t}+w_{r}$ and $w_{r}$ is the residual water content of the sample. So, (12) can be transformed into the following equation:

$$
\ln v_{e}=(3-D) \ln \frac{\psi_{a}}{\psi}+\ln \left(w_{s}-w_{r}\right)-\ln \left(T_{t}-t\right)
$$

At an arbitrary time $t_{1}$, the value of the matrix suction can be determined by (4), denoting as $\psi_{1}, v_{e}$ and $D$ should satisfy the following equation:

$$
\ln v_{e}=A(3-D)+B
$$

where $A$ and $B$ are constants, $A=\ln \left(\psi_{\mathrm{a}} / \psi_{1}\right)$, $B=\ln \left(w_{s}-w_{r}\right)-\ln \left(T_{t}-t_{1}\right)$.

Equation (14) shows that the evaporation rates of samples have a linear relationship with the fractal dimensions. In a published study [26], we investigated the relationship between fractal dimensions and evaporation rates for three soils at the same temperature, and the results showed that the evaporation rates of the three soils conformed to the same law with the fractal dimension, as shown in Figure 8(a). The correlation coefficient between the fitted line and the data was 0.89861 , and the slope of the fitted line was 0.04738 . We used this slope value to perform a linear fit to the data of Hunan sand at different ambient temperatures, where the soil fractional dimension was derived by Tao et al. [19], and the results are shown in Figure 8(b). The residual sum of squares (RSS) of the fitted results is $4.71631 \times 10^{-5}$ at an ambient temperature of $25^{\circ} \mathrm{C}, 7.22627 \times 10^{-5}$ at $30^{\circ} \mathrm{C}$, and 


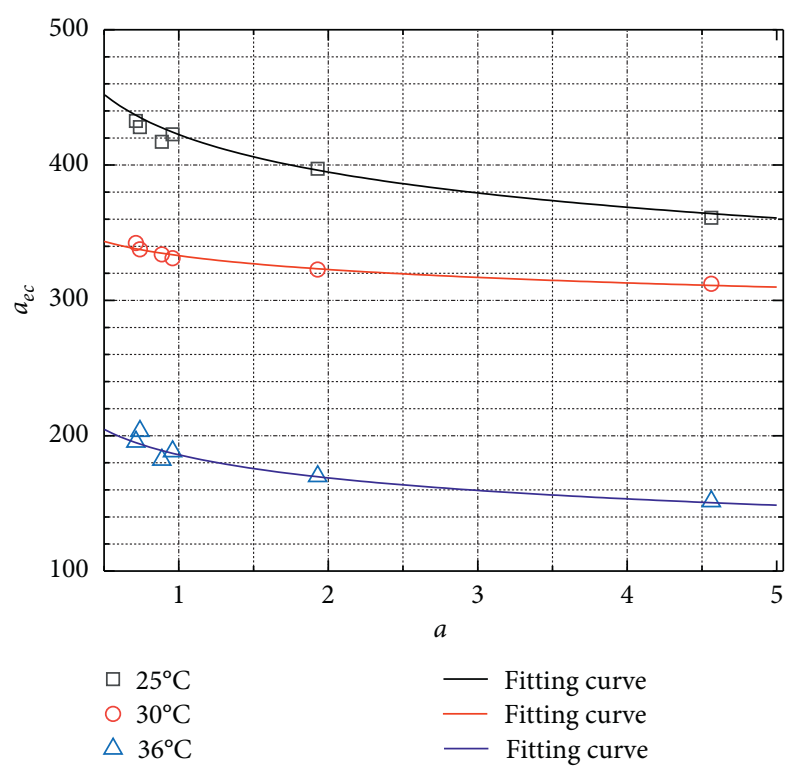

(a)

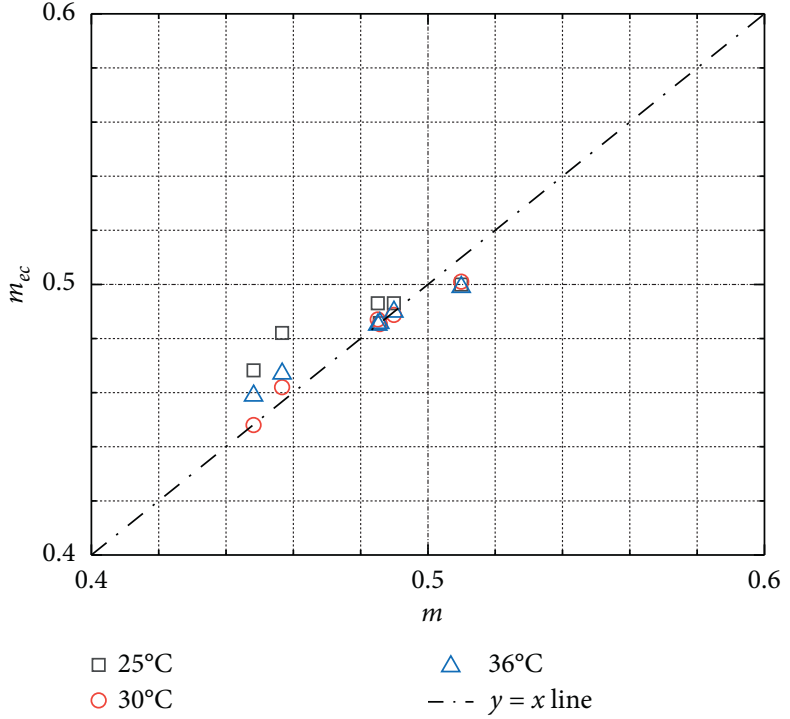

(b)

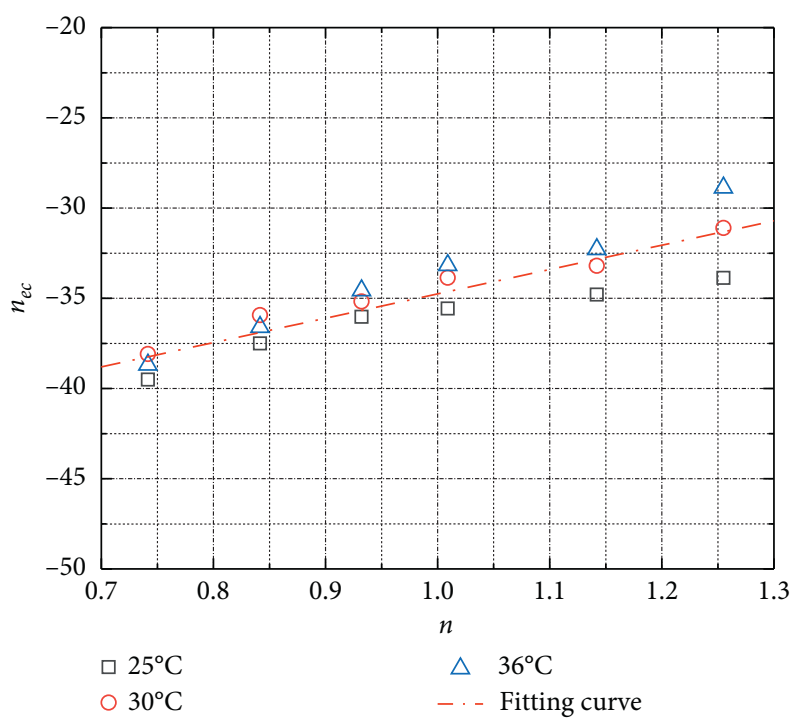

(c)

Figure 6: The result of parameter fitting. (a) $a$ versus $a_{e c}$, (b) $m$ versus $m_{e c}$, and (c) $n$ versus to $n_{e c}$.

$8.46807 \times 10^{-5}$ at $36^{\circ} \mathrm{C}$. It indicates that the evaporation rate and fractal dimension at each temperature are satisfied by (14). When the equation about evaporation rates versus fractal dimensions is determined, we can use the evaporation rates to calculate the fractal dimensions; furthermore, the soil water characteristic curves can be predicted. In addition, (14) also explains the effect of internal factors on the evaporation rate. Existing studies [5, 8, 27-33] analyzed the influences of thirteen internal factors on evaporation rates, such as saturation, clay content, density, pore size, soil color, and salinity. For soils with fractal characteristics, the fractal dimension is a parameter that can effectively reflect the internal composition of the soil. Thus, the fractal dimension is an internal factor that very directly affects the evaporation rate.
Predicting the soil water characteristic curve by (9) requires determining the residual water content of the soil sample, $w_{r}$. Tao et al. [34] suggest that the initial water content of the residual phase during soil water evaporation is almost identical to the residual water content obtained using the theoretical model. Similarly, Ouyang et al. [8] investigated the mechanism of soil water evaporation and their results also show that the water contents corresponding to the residual phase are the residual water contents. Figure 9 shows the residual water contents of soil samples at three ambient temperatures. It indicates that the residual water content increases with the increase of dry density, and the higher the ambient temperature, the smaller the residual water content. The soil water evaporation data were 


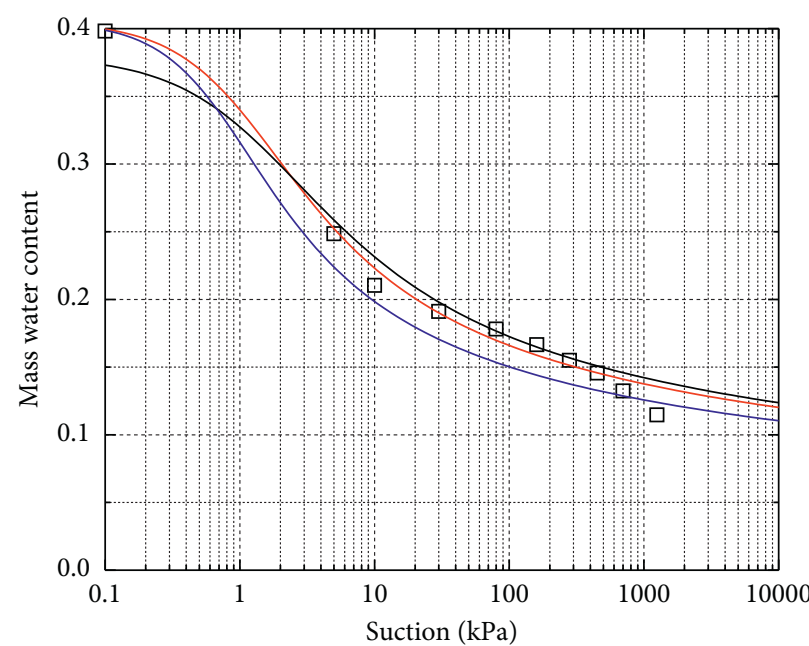

ㅁ $\mathrm{H} 1 \longrightarrow$ Predictive value of $30^{\circ} \mathrm{C}$ - Predictive value of $25^{\circ} \mathrm{C}-$ Predictive value of $36^{\circ} \mathrm{C}$

(a)

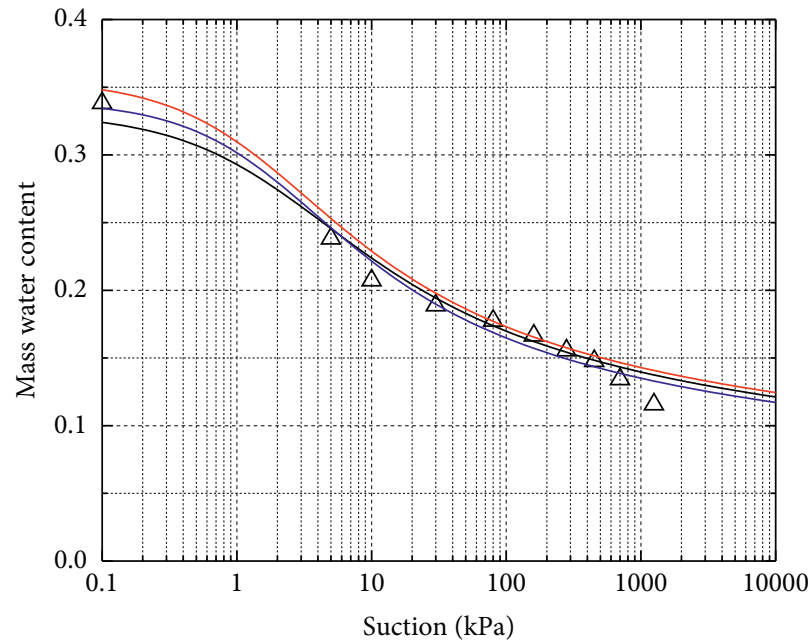

$\begin{array}{ll}\triangle \mathrm{H} 3 & \text { Predictive value of } 30^{\circ} \mathrm{C} \\ & \text { Predictive value of } 25^{\circ} \mathrm{C}\end{array}$

(c)

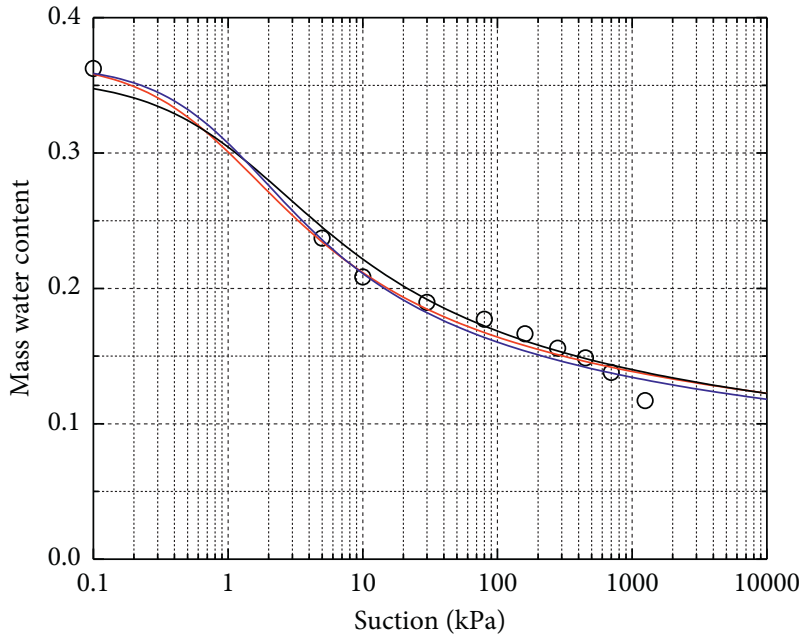

- $\mathrm{H} 2$ Predictive value of $30^{\circ} \mathrm{C}$ Predictive value of $25^{\circ} \mathrm{C}-$ Predictive value of $36^{\circ} \mathrm{C}$

(b)

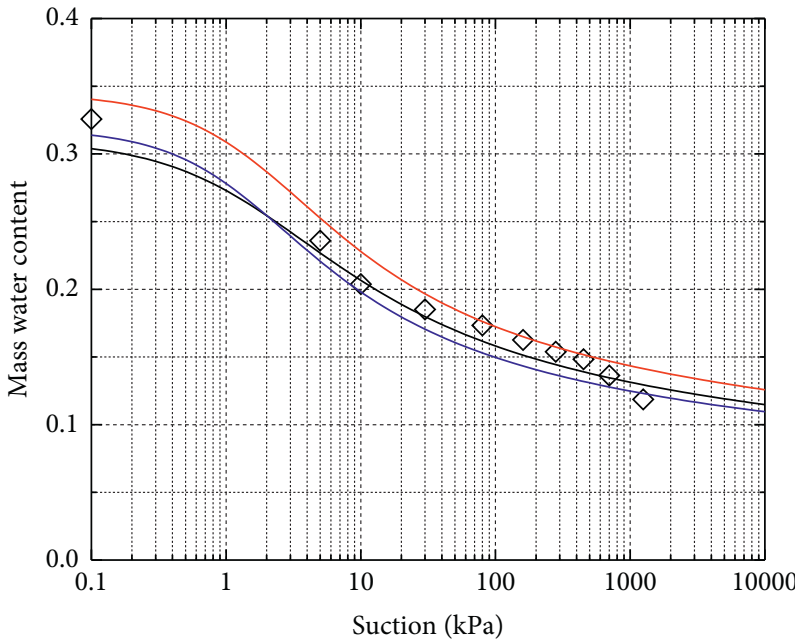

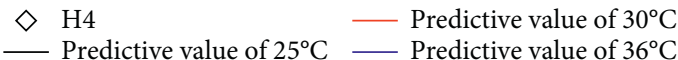

(d)

Figure 7: Continued. 


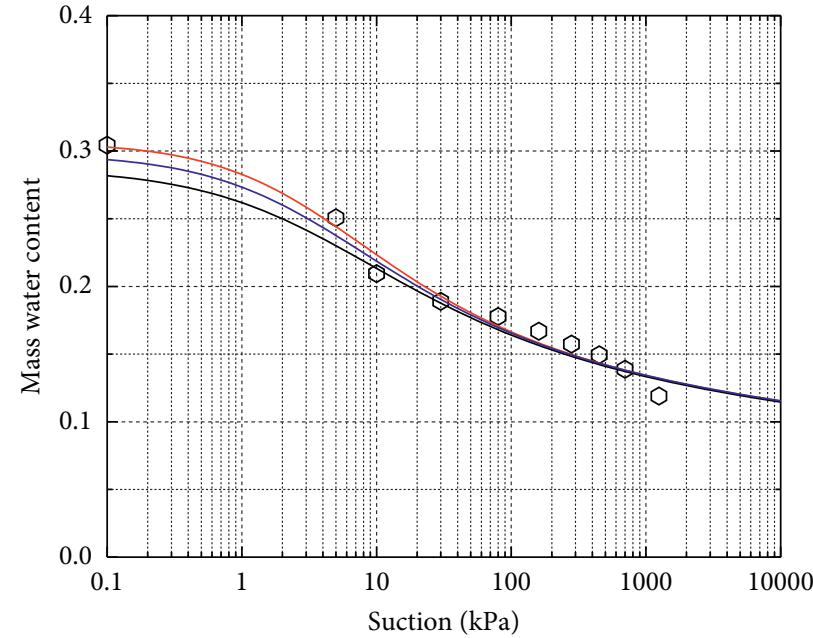

○ $\mathrm{H} 5$ Predictive value of $30^{\circ} \mathrm{C}$ Predictive value of $25^{\circ} \mathrm{C}$ Predictive value of $36^{\circ} \mathrm{C}$

(e)

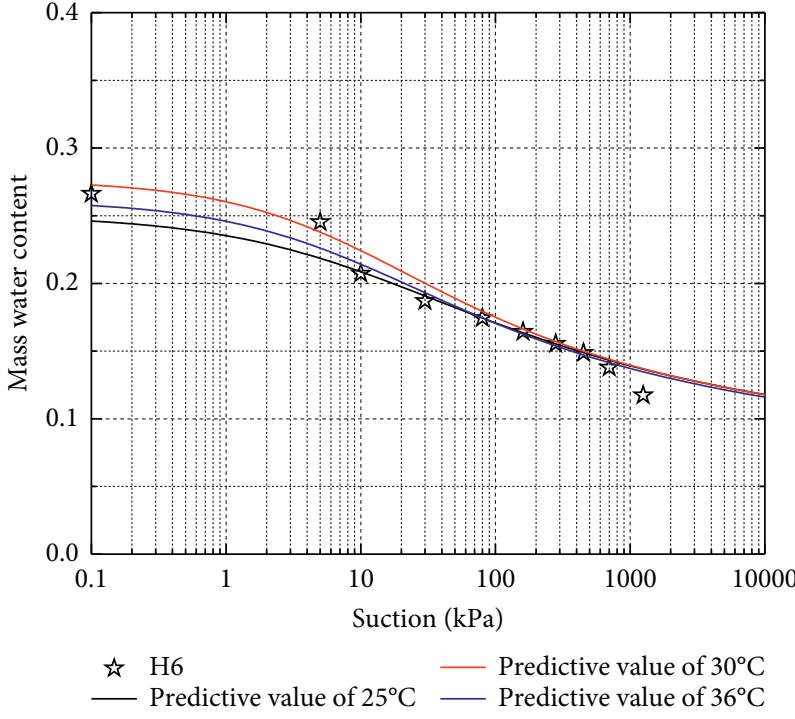

(f)

Figure 7: Results of predicted soil water characteristic curves. (a) The dry density of the specimen is $1.30 \mathrm{~g} / \mathrm{cm}^{3}$, (b) the dry density of the specimen is $1.35 \mathrm{~g} / \mathrm{cm}^{3}$, (c) the dry density of the specimen is $1.40 \mathrm{~g} / \mathrm{cm}^{3}$, (d) the dry density of the specimen is $1.45 \mathrm{~g} / \mathrm{cm}^{3}$, (e) the dry density of the specimen is $1.50 \mathrm{~g} / \mathrm{cm}^{3}$, and (f) the dry density of the specimen is $1.60 \mathrm{~g} / \mathrm{cm}^{3}$.

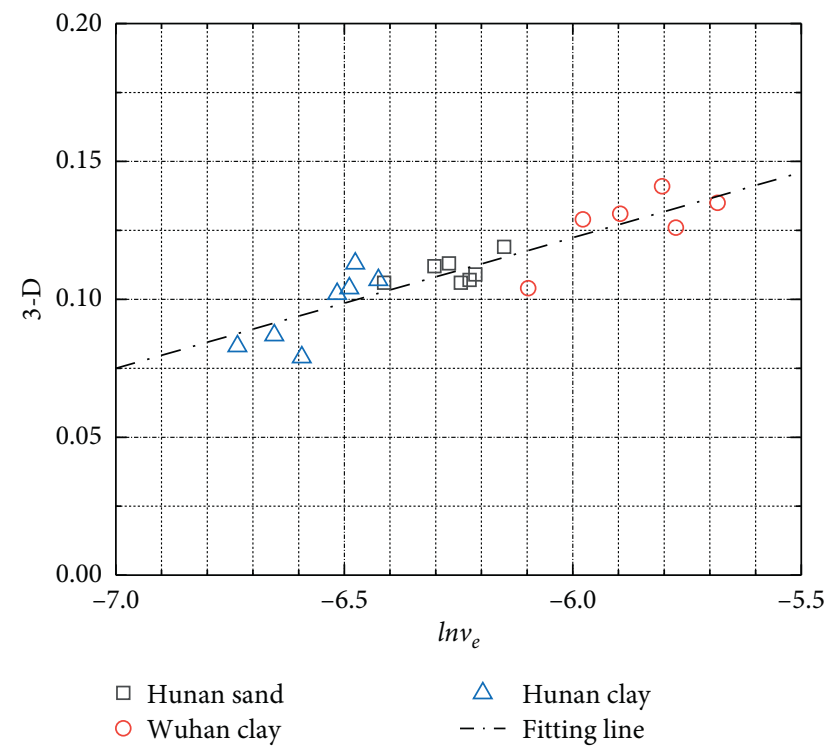

(a)

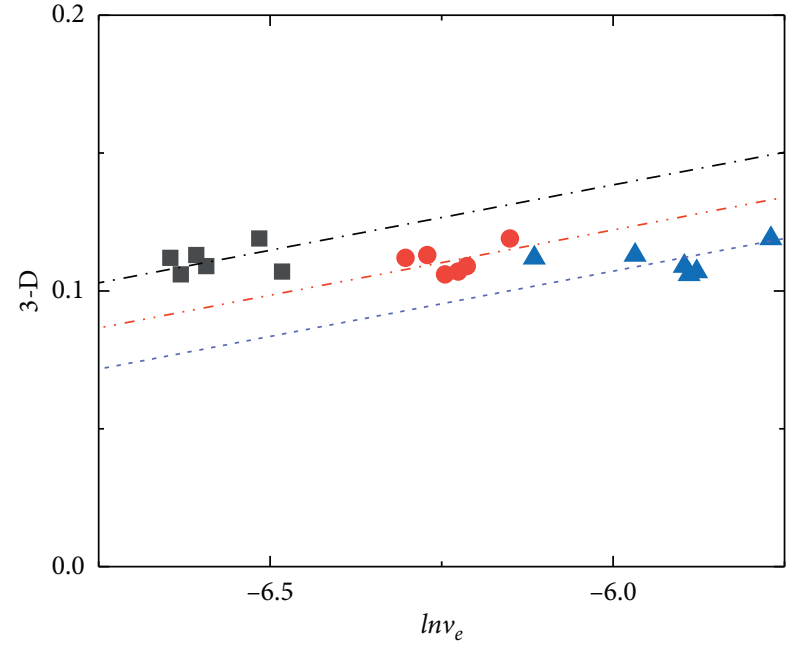

- $25^{\circ} \mathrm{C}$ ambient temperature

- $30^{\circ} \mathrm{C}$ ambient temperature

- $36^{\circ} \mathrm{C}$ ambient temperature

(b)

Figure 8: The functional relationship between $\ln v_{e}$ and 3D.

converted into the expression form of effective saturation, as seen in Figure 10.

We substitute the cumulative time series of evaporation experiments into (4) to obtain the corresponding matrix suction series. Then, we combine it with the water content series measured by the soil water evaporation tests into a set of data on suctions versus water contents, that is, the predicted value of the soil water characteristic curves, as shown in Figure 11. Comparing the predicted values with measured data, it can be found that the predicted soil water characteristic curves using the soil water evaporation at different temperatures do not differ much, and the consistency between the predicted and measured values is high. In the high suction range, the predicted values tend to be smaller than the measured values; this is due to the simplified consideration of deceleration rate phase, which has a much shorter 


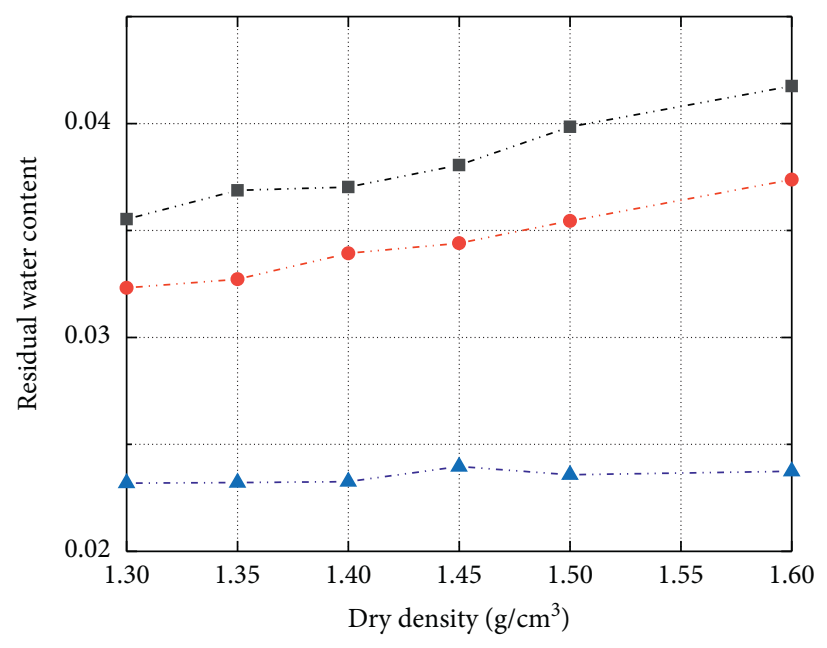

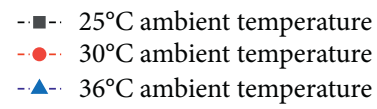

Figure 9: Residual water content of soil water evaporation test.

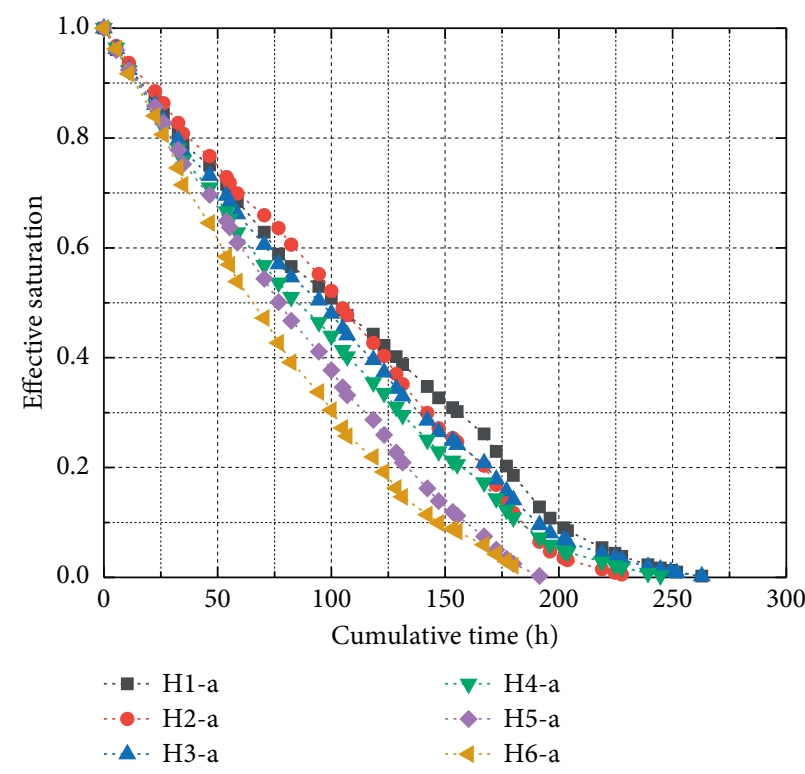

(a)

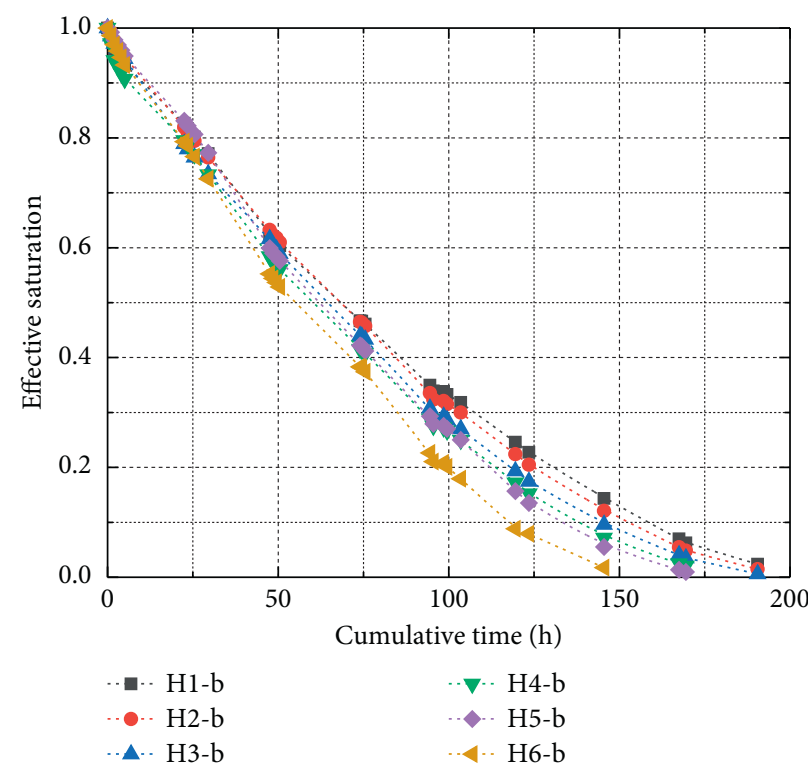

(b)

Figure 10: Continued. 


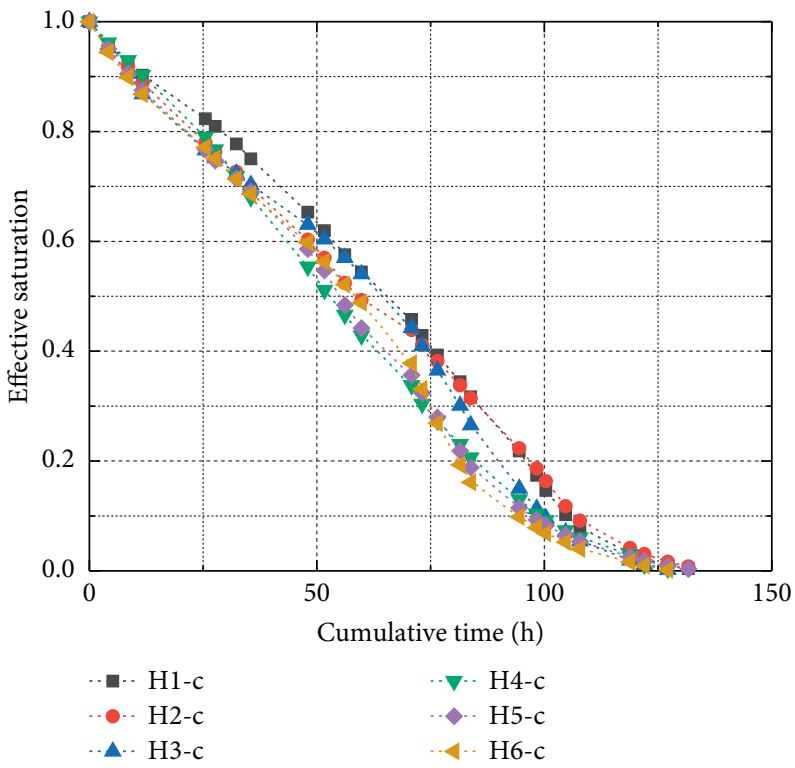

(c)

Figure 10: Variation of effective saturation with cumulative time of soil water evaporation. (a) $25^{\circ} \mathrm{C}$ ambient temperature, (b) $30^{\circ} \mathrm{C}$ ambient temperature, and (c) $36^{\circ} \mathrm{C}$ ambient temperature.

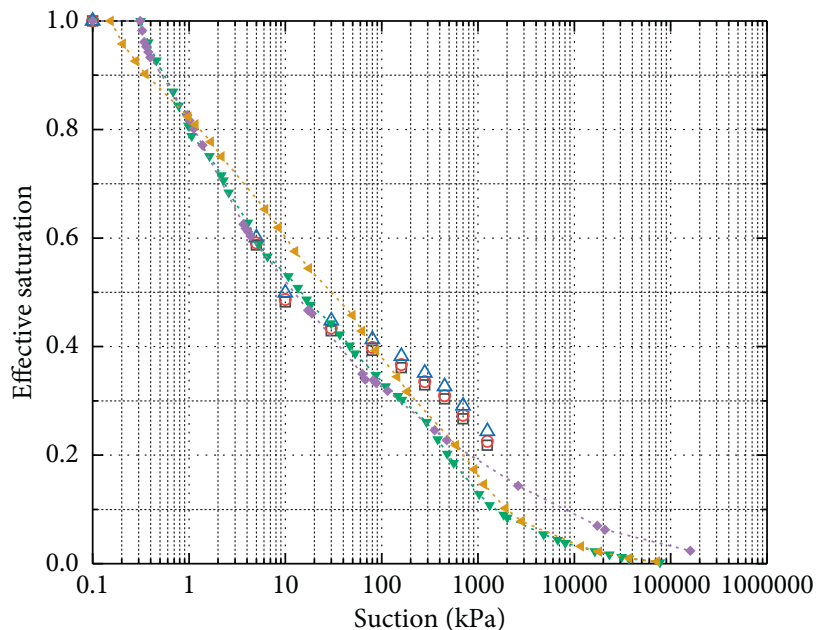
$\square$ Measured value of $25^{\circ} \mathrm{C}$
- Measured value of $30^{\circ} \mathrm{C}$
$\triangle$ Measured value of $36^{\circ} \mathrm{C}$
.... Predicted value of $25^{\circ} \mathrm{C}$
... Predicted value of $30^{\circ} \mathrm{C}$
..4. Predicted value of $36^{\circ} \mathrm{C}$

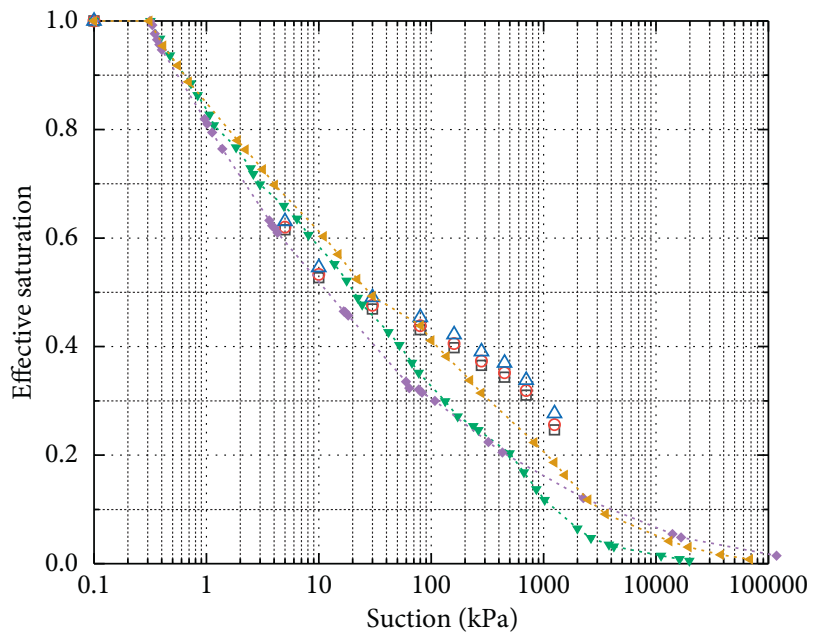
ㅁ Measured value of $25^{\circ} \mathrm{C}$
- Measured value of $30^{\circ} \mathrm{C}$
-.. Predicted value of $25^{\circ} \mathrm{C}$
-. Predicted value of $30^{\circ} \mathrm{C}$
$\triangle$ Measured value of $36^{\circ} \mathrm{C} \quad \ldots 4$... Predicted value of $36^{\circ} \mathrm{C}$

(a)

(b)

Figure 11: Continued. 

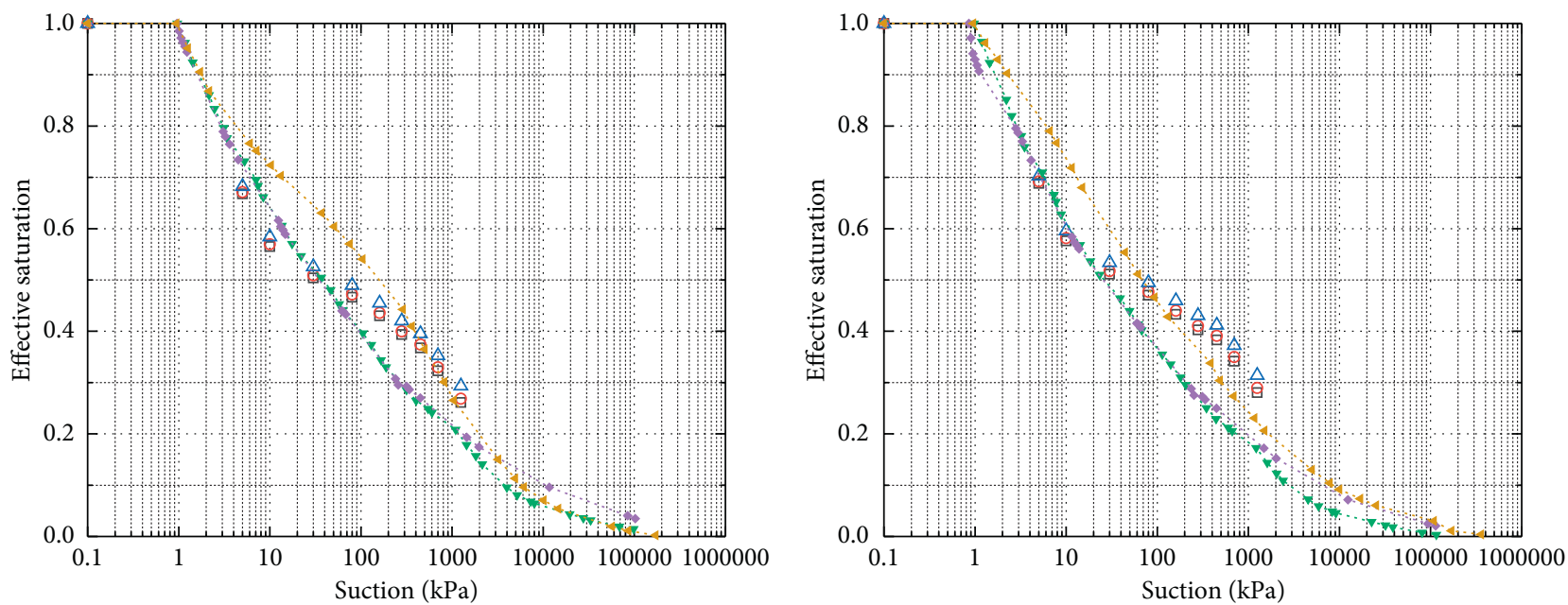

\begin{abstract}
- Measured value of $25^{\circ} \mathrm{C} \quad$.... Predicted value of $25^{\circ} \mathrm{C}$
- Measured value of $30^{\circ} \mathrm{C} \quad$.... Predicted value of $30^{\circ} \mathrm{C}$

$\triangle$ Measured value of $36^{\circ} \mathrm{C} \quad$.4. Predicted value of $36^{\circ} \mathrm{C}$
\end{abstract}

(c)

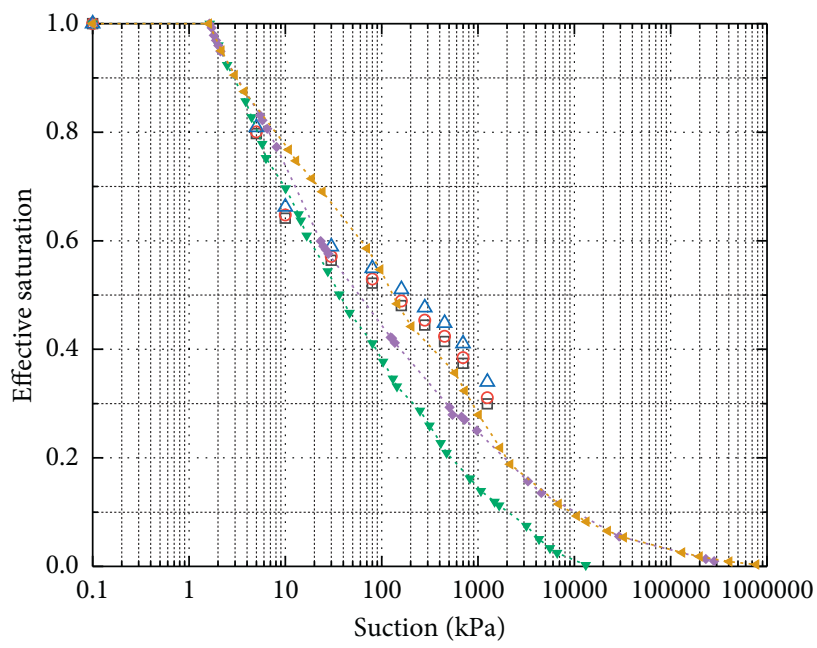

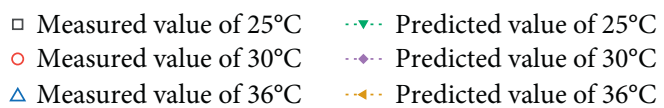

(e)

\begin{abstract}
口 Measured value of $25^{\circ} \mathrm{C} \quad$... . Predicted value of $25^{\circ} \mathrm{C}$
- Measured value of $30^{\circ} \mathrm{C} \quad \cdots \quad$ Predicted value of $30^{\circ} \mathrm{C}$

$\triangle$ Measured value of $36^{\circ} \mathrm{C} \quad \ldots \quad$ Predicted value of $36^{\circ} \mathrm{C}$
\end{abstract}

(d)

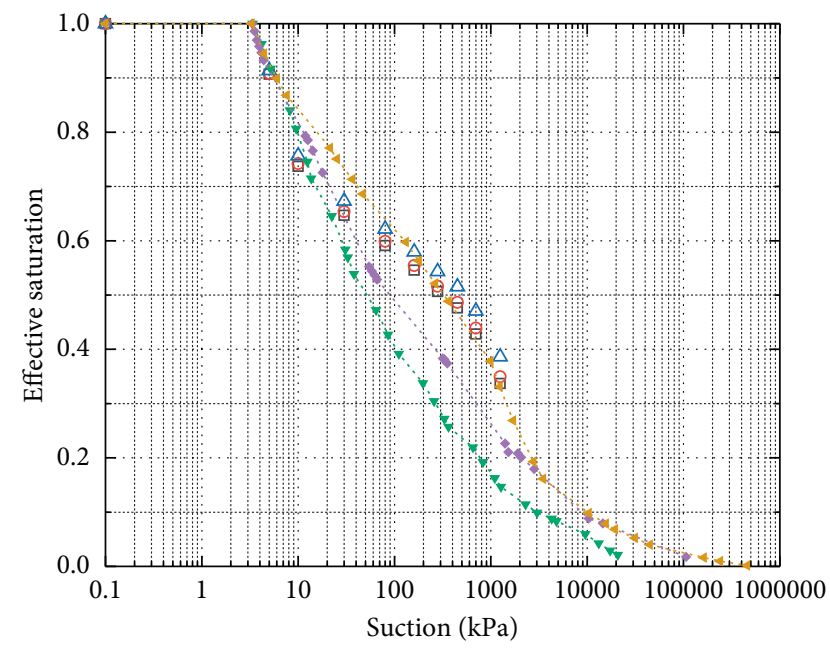

口 Measured value of $25^{\circ} \mathrm{C} \quad$..... Predicted value of $25^{\circ} \mathrm{C}$

- Measured value of $30^{\circ} \mathrm{C} \quad \cdots$ Predicted value of $30^{\circ} \mathrm{C}$

$\triangle$ Measured value of $36^{\circ} \mathrm{C} \quad 4 \quad$ Predicted value of $36^{\circ} \mathrm{C}$

(f)

Figure 11: Comparison of predicted results with measured data. (a) The dry density of the specimen is $1.30 \mathrm{~g} / \mathrm{cm}^{3}$, (b) the dry density of the specimen is $1.35 \mathrm{~g} / \mathrm{cm}^{3}$, (c) the dry density of the specimen is $1.40 \mathrm{~g} / \mathrm{cm}^{3}$, (d) the dry density of the specimen is $1.45 \mathrm{~g} / \mathrm{cm}^{3},(\mathrm{e})$ the dry density of the specimen is $1.50 \mathrm{~g} / \mathrm{cm}^{3}$, and (f) the dry density of the specimen is $1.60 \mathrm{~g} / \mathrm{cm}^{3}$.

duration compared to the other two phases. The time required for the soil to change from supersaturated to quasisaturated state is also an important cause of this error. In addition, a stable test environment and accurate measurement of the weight loss of the soil sample have a huge impact on the predicted results.

The root mean square error (RMSE) was used to evaluate the prediction accuracy of this prediction method, which was calculated as shown in (15). The prediction results under two suction ranges $(0-100 \mathrm{kPa}$ and $0-1250 \mathrm{kPa})$ were evaluated, which represent the prediction performance at low suction and at full suction range, respectively. The influence of ambient temperature on the predicted results was evaluated by comparing the predicted results at each temperature, and the results are shown in Table 3. In low suction range $(0-100 \mathrm{kPa})$, the soil water characteristic curve predicted by using evaporation curve with low ambient temperature is more accurate, because the lower the ambient temperature, the smaller the evaporation rate is. So, we can monitor the changes in the water content of samples more accurately. However, the times of operations to remove the specimens for weighing was increased. Since the experimental errors generated during the measurement process have a gradual cumulative effect on the predicted results, this 
TABLe 3: Prediction accuracy at low suction range and full suction range.

\begin{tabular}{lcccrcr}
\hline & \multicolumn{2}{c}{ Ambient temperature $\left({ }^{\circ} \mathrm{C}\right)$} \\
Specimen number & \multicolumn{2}{c}{25} & \multicolumn{2}{c}{30} \\
& & \multicolumn{2}{c}{ RMSE } \\
& $0-100 \mathrm{kPa}$ & $0-1250 \mathrm{kPa}$ & $0-100 \mathrm{kPa}$ & $0-1250 \mathrm{kPa}$ & $0-100 \mathrm{kPa}$ & $0-1250 \mathrm{kPa}$ \\
\hline H1 & 0.03017 & 0.06520 & 0.03169 & 0.05754 & 0.06079 & 0.06721 \\
H2 & 0.04912 & 0.10083 & 0.06357 & 0.10478 & 0.03677 & 0.06576 \\
H3 & 0.05113 & 0.07321 & 0.04635 & 0.07261 & 0.10063 & 0.07519 \\
H4 & 0.04429 & 0.09758 & 0.04360 & 0.09447 & 0.08706 & 0.08475 \\
H5 & 0.05722 & 0.13342 & 0.05297 & 0.09750 & 0.07763 & 0.06336 \\
H6 & 0.07804 & 0.15758 & 0.05203 & 0.09488 & 0.04786 & 0.04578 \\
\hline
\end{tabular}

leads to a surge in the error of the final predicted results. The higher the ambient temperature, the faster the process of the evaporation experiment, where the deceleration rate phase takes up less time. The evaporation curve can be regarded as two linear variations, which is closer to the theory of this study. Therefore, the predicted soil water characteristic curves in the full suction range have higher accuracy when the ambient temperature is higher. In the subsequent study, the prediction accuracy of the soil water characteristic curve can be effectively improved by reducing the times of removing the specimens for weighing and the reducing experimental errors generated during the test:

$$
\operatorname{RMSE}=\sqrt{\frac{\sum_{i=1}^{p}\left(x_{i}-x_{i}^{\prime}\right)^{2}}{p}},
$$

where $x_{i}$ is the $i$ th predicted value of effective saturation, $x_{i}{ }_{i}$ is the $i$ th measured value of effective saturation, and $p$ is the number of measurement points.

\section{Conclusion}

In this study, soil water evaporation curves and soil water characteristic curves of Hunan sand were tested, analyzed, and compared. By studying soil water evaporation at different dry densities and ambient temperatures, the connections between soil water evaporation and soil water characteristic curve are revealed. Based on two theoretical models, methods to predict soil water characteristic curves using soil water evaporation curves are proposed. The following conclusions can be drawn.

(1) The soil water evaporation rates increase with the increasing ambient temperature, and the higher the dry density, the smaller the evaporation rate. The fractional dimensions are an important parameter to indicate the pore structure. It shows the influence of many internal factors on the microstructure of the soil. This study shows that the evaporation rates are related to the fractional dimensions, and in soil with larger fractional dimensions, the evaporation rates are larger.

(2) The initial water contents of the residual phase in soil water evaporation process are the residual water contents of the soil, and its value increases with the increase of the dry density. For the soil with the same dry density, the higher the ambient temperature is, the smaller the residual water content of the soil is.

(3) During the constant rate phase, the water content is related to the cumulative time of soil water evaporation, and the cumulative time can be replaced by the matrix suction using (4). This leads to a method for predicting soil water characteristic curves using soil water evaporation data. Verification of the method was carried out using soil samples with six dry densities at three ambient temperatures, and the results showed that the predicted values were in good agreement with the measured data.

\section{Data Availability}

The data used to support the findings of this study are available from the corresponding author upon request.

\section{Additional Points}

Research Highlights. The relationship between soil water evaporation curves and soil water characteristic curves is investigated. The equation for the conversion from cumulative evaporation time to matrix suction was derived based on fractal theory. Two methods to predict soil water characteristic curves based on evaporation curves were developed.

\section{Conflicts of Interest}

The authors declare that there are no conflicts of interest regarding the publication of this paper.

\section{Acknowledgments}

The research was funded by the National Natural Science Foundation of China (Grant no. 51978249).

\section{References}

[1] P. Sattler and D. G. Fredlund, "Use of thermal conductivity sensors to measure matric suction in the laboratory," $\mathrm{Ca}$ nadian Geotechnical Journal, vol. 26, no. 3, pp. 491-498, 1989.

[2] J. D. Nelson and D. J. Miller, Expansive Soils: Problems and Practice in Foundation and Pavement Engineering, John Wiley, New York, NY, USA, 1992. 
[3] R. Bahar and S. Kenai, "Analysis of some problems of foundations and retaining walls in clay soils," in Proceeding of International Symposium on Drought and Constructions, vol. 1-3, pp. 413-418, Paris, France, September 2008.

[4] C. S. Tang, B. Shi, and K. Gu, "Experimental investigation on evaporation process of water in soil during drying," Journal of Engineering Geology, vol. 19, no. 6, pp. 875-881, 2011.

[5] H. Trabelsi, "Evaporation rate dependence with saturation degree," In: International Congress and Exhibition. Sustainable Civil Infrastructures: Innovative Infrastructure Geotechnology, Springer, Cham, Switzerland, 2017.

[6] N. Lu, J. L. William, C. F. Wei, L. Hou, and W. X. Jian, Unsaturated Soil Mechanics, Higher Education Press, Beijing, China, 2012.

[7] D. A. Sun, W. Sun, and L. Xiang, "Effect of degree of saturation on mechanical behaviour of unsaturated soils and its elastoplastic simulation," Computers and Geotechnics, vol. 37, no. 5, pp. 678-688, 2010.

[8] P. Q. Ouyang, C. S. Tang, D. Y. Wang, S. K. Xu, and B. Shi, "Advances on soil moisture evaporation," Rock and Soil Mechanics, vol. 37, no. 3, pp. 625-636, 2016.

[9] J. Dalton, "Experimental essays on the constitution of mixed gases; on the force of steam or vapor from water and other liquids at different temperatures, both in a Torricellian vacuum and in air; on evaporation and on the expansion of gases by heat," Memoirs and Proceedings of the Manchester Literary and Philosophical Society, Nabu Press, vol. 5, no. 11, , pp. 535-602, Manchester, 1802.

[10] H. L. Penman, "Natural evapotranspiration from open water, bare soil and grass," Proceedings of the Royal Society of London (Series A), vol. 193, pp. 120-146, 1948.

[11] M. J. Fox, "A technique to determine evaporation from dry stream beds," Journal of Applied Meteorology, vol. 7, no. 4, pp. 697-701, 1968.

[12] Y. M. Denisov, A. I. Sergeev, G. A. Bezborodov, and Y. G. Bezborodov, "Moisture evaporation from bare soils," Irrigation and Drainage Systems, vol. 16, no. 3, pp. 175-182, 2002.

[13] N. Q. Xin, "Study on soil evaporation observation method," Acta Pedologica Sinica, vol. 10, no. 4, pp. 388-400, 1962.

[14] W. K. Song and W. Q. Ding, "Research progress on test apparatus for water evaporation from soil," Subgrade Engineering, vol. 5, pp. 1-4, 2013.

[15] J. T. Ritchie, "Model for predicting evaporation from a row crop with incomplete cover," Water Resources Research, vol. 8, no. 5, pp. 1204-1213, 1972.

[16] G. Tao and J. Zhang, "Two categories of fractal models of rock and soil expressing volume and size-distribution of pores and grains," Science Bulletin, vol. 54, no. 23, pp. 4458-4467, 2009.

[17] A. J. Katz and A. H. Thompson, "Fractal sandstone pores: implications for conductivity and pore formation," Physical Review Letters, vol. 54, no. 12, pp. 1325-1328, 1985.

[18] N. Sarkar and B. B. Chaudhuri, "An efficient differential boxcounting approach to compute fractal dimension of image," IEEE Transactions on Systems, Man, and Cybernetics, vol. 24, no. 1, pp. 115-120, 1994.

[19] G. Tao, Y. Chen, L. Kong, H. Xiao, Q. Chen, and Y. Xia, “A simple fractal-based model for soil-water characteristic curves incorporating effects of initial void ratios," Energies, vol. 11, no. 6, p. 1419, 2018.

[20] D. G. Fredlund and A. Xing, "Equations for the soil-water characteristic curve," Canadian Geotechnical Journal, vol. 31, no. 4, pp. 521-532, 1994.
[21] R. Michel and S. Garrison, "Fractal fragmentation, soil porosity, and soil water properties: I. theory," Soil Science Society of America Journal, vol. 55, no. 5, pp. 1231-1238,, 1991.

[22] E. Perfect, N. B. Mclaughlin, B. D. Kay, and G. C. Topp, "An improved fractal equation for the soil water retention curve," Water Resources Research, vol. 32, no. 2, pp. 281-287, 1996.

[23] J. W. Crawford, N. Matsui, and I. M. Young, "The relation between the moisture-release curve and the structure of soil," European Journal of Soil Science, vol. 46, no. 3, pp. 369-375, 2010.

[24] N. R. A. Bird, E. Perrier, and M. Rieu, "The water retention function for a model of soil structure with pore and solid fractal distributions," European Journal of Soil Science, vol. 51, no. 1, pp. 55-63, 2010.

[25] X. F. Xu and P. Dong, "Fractal models for the soil-water characteristics of unsaturated soils," Rock Soil Mechanics, vol. 2002, no. 4, pp. 400-405, 2002.

[26] G. L. Tao, Q. Wang, Z. Z. Zhu et al., "A method for predicting fractional dimensions based on the soil-water evaporation laws," CN patent 202011208529, vol. 4, 2020.

[27] G. W. Wilson, D. G. Fredlund, and S. L. Barbour, "The effect of soil suction on evaporative fluxes from soil surfaces," Canadian Geotechnical Journal, vol. 34, no. 1, pp. 145-155, 1997.

[28] G. W. Wilson, D. G. Fredlund, and S. L. Barbour, "Coupled soil-atmosphere modelling for soil Evaporation," Canadian Geotechnical Journal, vol. 31, no. 2, pp. 151-161, 1994.

[29] F. Diaz, C. C. Jimenez, and M. Tejedor, "Influence of the thickness and grain size of tephra mulch on soil water evaporation," Agricultural Water Management, vol. 74, no. 1, pp. 47-55, 2005.

[30] E. A. Fisher, "Some factors affecting the evaporation of water from soil," The Journal of Agricultural Science, vol. 13, no. 2, pp. 121-143, 1923.

[31] M. K. Kayyal, "Effect of the moisture evaporative stages on the development of shrinkage cracks in soil," in Proceedings of First International Conference on Unsaturated Soils, pp. 373-379, Paris, France, September 1995.

[32] T. R. Oliver and D. M. Newitt, "The measurement of suction potentials and moisture distribution in drying granular soils," Transactions of the Institution of Chemical Engineers, vol. 27, pp. 9-18, 1949.

[33] D. Hillel, Introduction to Environmental Soil Physics, Elsevier Academic Press, Amsterdam, Netherlands, 2004.

[34] G. L. Tao, J. Li, X. S. Zhuang, H. L. Xiao, X. L. Cui, and W. S. Xu, "Determination of the residual water content of SWCC based on the soil moisture evaporation properties and micro pore characteristics," Rock and Soil Mechanics, vol. 39, no. 4, pp. 1256-1262, 2018. 